\title{
PREDICTION OF EARTHQUAKES AND REDUCING DAMAGES
}

\author{
Krishna Kumar ${ }^{1}$ \\ ${ }^{I}$ Mtech $4^{\text {th }}$ semester, Ganga Institute of Technology \& Management, Kablana, Jhajjar, Haryana, India
}

\begin{abstract}
An earthquake also known as tremor or temblor is the result of a sudden release of energy in the Earth's crust that creates seismic waves. An earthquake may cause injury and loss of life, roads and bridge damage, general property damage, and collapse or destabilization of buildings. The objective of earthquake engineering is to foresee the impact of earthquakes on buildings and other structures and to design such structures to minimize the risk of damage. Existing structures can be modified by seismic retrofitting to improve their resistance to earthquakes. Methodologies to anticipate earthquakes require to be developed, so that early warning can be issued to avoid heavy casualties and major damages.
\end{abstract}

Keywords: Earthquake, seismic retrofitting, seismic waves

\section{INTRODUCTION}

The recurrences of earthquakes in Uttarkashi \& Latur districts of India, Indonesia and Japan (Tohoku) have caused panic and fear among us leaving an unparalleled psychological impact on humanity. The colossal devastations have challenged the man's ability to face nature's ravages, which calls upon a serious review of the understanding about the natural phenomena by scientists, engineers and planners. Suddenness of earthquakes occurrence make them most dreaded causing instantaneous losses of life and property. Thus there is an urgent need to tackle this menace either reducing or eliminating the risks. The losses due to earthquakes can be reduced through various prediction, modification or mitigation means.

\section{PREDICTION}

Prediction means forecasting of the future earthquakes of specific magnitude at specific location and time. It can be long term (months or years before the occurrence of event) or short term (days or weeks before).Long term prediction leads to higher priorities being given to remedial measures to save life and property in the threatened area. People are prepared in advance to face the rage of nature. Three broad areas considered to be more prone to earthquake as compared to, rest of the world are demarcated as seismic belts. About more than $2 / 3$ rd of all the earthquakes occur in these regions. Further attempts in the identification and demarcation of seismic gaps with the help of historical records and regular monitoring and recording of rock energies will approximately give the potential site of occurrence.

Development of new cracks in the rocks due to high accumulation of energy may pinpoint the site where release of energy may take in near future. The expected time of failure may give the time for the occurrence of event.

Seismic risk maps prepared on the basis of historical earthquake records and estimates of geodynamic activity in the region may help in locating the potentially dangerous areas. The repetition of earthquakes after regular interval of time i.e. seismic cycles may help in assessing the risk, the type of structure and population density must be considered. Statistical techniques are also employed to asses the earthquake risks.

Long range predictions have helped in the prediction of Broach earthquake of 23-3-1970 in Gujarat. Newspapers reported that a senior research officer from Pune,Mr.Arun Bapat has claimed that he had used the Seismic Grid Method successfully to predict the chances of occurrence of the Garhwal quake. He had mentioned in the "Physics education" issue of oct-dec; 1990 that an earthquake of the magnitude in the range 7-7.5 could occur in the grid 31-32 N $\&$ 78-79 $\mathrm{E}$ in near future. The S.G.M consists of observing the number of earthquakes per grid magnitude range per decade. This is supported by a model which envisages different stages of seismic gaps establishment stage, development stage, maturity stage and occurrence of the event. Short term prediction leads to general emergency preparedness putting all protection measures on full alert and other temporary actions to reduce the disaster effect in the risk area to minimum. For short term predictions the precursors of earthquakes are useful indicators of time of occurrence of major shock. The time of occurrence of new cracks in rocks, foreshocks, increased radon gas escape from the wells and other geohydrochemical changes, geomagnetic anomalies, anomalous changes in electrical resistivity of rocks and water level changes and unusual animal behavior are some of them. Short term prediction was effectively used in saving thousands of lives in China in 1975 but the approach failed in predicting the Tansang earthquake. Prof James Brune of U.S.A. and Prof Vinod gaur of department of ocean development, New Delhi has predicted that another earthquake may hit the Garhwal region very soon. The recent earthquakes may have marked the onset of a precursory phase preparatory to major earthquake of magnitude greater than 8. Prof. Brune estimated that it would take three major earthquakes to release the tension which has been building up along the seismic map. 
There are frightening predictions which no scientist can make with the present state of art, controversial status of the gap theory and the nascent level of the physics of earthquake process. But according to Dr. S.N. Chatterji, Director, seismology division of Indian meteorological department, there would not be another earthquake as most of its energy had been dissipated by now.

\section{MODIFICATION}

Modification of earthquakes is based on the belief that we can relieve the growing strain in rocks by safely triggering small tremors artificially in stressed rocks. The injection of water in a fault zone reduces the friction and is followed by a series of small tremors, thus rendering the area as less dangerous.

\section{MITIGATION}

Mitigation is an effort to reduce or eliminate the damage to our life and property by the earthquake. Various types of mitigation measures are suggested for protecting man and structures depending on the type of structure, population density and geology of the region and the magnitude of the potential earthquakes. Efforts should be made to keep a reasonable balance between safety and economy of people. The mitigation steps are usually taken in accordance with the nature and effect of the seismic waves on structures and the response of the structures to the waves. In addition the nature of medium, geological structures, properties and behavior of soils and rocks of the area are also considered. The input of data from geologists and architects to design safe earthquake resistant structures, better known as aseismic structures. It will also help in testing the response of structures to the potential ground motion. The planners can use the information provided by these scientists and engineers to plan and enforce some regulations on the safe construction and designing of structures in the threatened regions. (The Indian standards codes IS: 4326 and IS 18932002 are examples of such efforts on this direction.)

\section{SAFETY MEASURES FOR CONSTRUCTION}

\section{OF BUILDINGS IN EARTHQUAKE PRONE}

\section{AREA}

The poor quality of house construction with large stone roofing was largely responsible for high death toll in the Garhwal quake. The heavy slate roofing collapsed as the quake hit the area when people were asleep. However, brick buildings made with mortar mixture didn't collapse but could have only developed cracks. Thus it showed that earthquake disasters could be countered by building appropriate earthquake resistant structures. It is the horizontal component of ground acceleration that causes most of the damage to buildings. Vertical movement of buildings does not worry much to designers as the buildings are usually strong enough for the vertical loads. Moreover the earthquakes load in the horizontal direction is a function of the height of the centre of gravity of structural mass above ground level and consequently the area of base also affects the designers approach. Since the seismic forces generated on a structure depends on the properties of a structures itself besides of course the intensity of earthquake. The structural and architectural designers have two choices: (1) to make the structure strong (2) To reduce the seismic force by adjusting the structural stiffness. Most of the mitigation efforts since long back have been devised to counter fatalities caused by one of these. For instance, the walls of buildings were made very thick in old days. This made the buildings too heavy to be shaken by a small or moderate ground tremor. Subsequently the economy of the construction led to reduction of structural mass. The required modifications in the other aspects of construction like use of construction materials such as timber which absorbs stress and provide a light framed shape. The frame could overturn along with its foundation but would not collapse. The best suitable construction material for earthquake resistance should have high ductility, high strength/weight ratio, homogeneity, orthotropic and ease in making full strength connections. Lowering of the centre of gravity directly relates to forces in lower storeys. The pyramid shape of many buildings in seismic zones is outcome of this construction. The pyramids have a much wider base and a low centre of gravity. Buildings were also made immune to earthquakes hazards often by use of ductile structural arrangement. The design would be made to resist the moderate seismic loads and the material would undergo plastic deformations when subjected to a severe ground shaking. This approach was called as fail safe design but it demanded more careful design of joints as the joints are the first to yield as the failure advances. Prefabricated structural units required proper connections in a fail safe design. In recent times, most of the research efforts have been concentrated on developing the base isolation technique. In this approach, the building is isolated from its foundation by a layer of isolation bearings and the earthquake energy is thus prevented from entering into the super storey. This is analogous to a battle ship floating over the ocean. The ground shakes but the building remains unaffected. But the most important of all, we have to devise our own indigenous methods to get rid of the syndrome. The buildings are mostly constructed in a traditional manner without the help of qualified professionals in their design and construction. It has been observed in many quake ravaged areas of Garhwal that most of the houses having roofs of slate with wooden framework had collapsed in the earthquake. Therefore, a set of recommendations based on the observation of such buildings during an earthquake should be given to the inhabitants. If at all stones are to be used in these areas, suitable mortar with sufficient strength was a must for house construction to withstand shocks. Simple remedies have been suggested in the past suited to local conditions, availability of construction materials and the state of art in building construction prevailing at that time. Central building research Institute, Roorkee a pioneer in building research in India is heading on its way to meet this challenge of the violent forces of nature to humanity. Some attempts have already been made in this direction and much more efforts are ongoing to make ourselves immune to such catastrophic happenings. Some remedial measures need to 
be taken after the quake has occurred in a region to avoid further danger to life, and property in future. The precaution should be taken in the portions which have been rendered weak and prone to landslides because of the newly developed cracks and water accumulation or seepages.

\section{CONCLUSION}

Earthquakes proved to be fatalistic because of their proximity to either heavily populated areas or the ocean, where earthquakes often create tsunamis that can devastate communities in a very large area. The aftermath of post earthquake may bring disease, lack of necessities etc., hence education and awareness among society about earthquakes is essential. Buildings and structures must be designed with qualified structural consultants. Codal provisions required to be followed while design, to impart sufficient ductility and reserve strength, so that seismic response of the structure during an earthquake must be within desirable limits. Adequate disaster management programme should be implemented. Earthquake insurance can provide building owners with financial protection against losses resulting from earthquakes. Emergency management strategies can be employed by a government or organization to mitigate risks and prepare for consequences.

\section{FUTURE SCOPE}

Methods can be developed for predicting the time and place in which earthquake will occur. Understanding the earth crust behavior for well-understood faults the probability that a segment may rupture during the next few decades can be estimated. Most earthquakes form part of a sequence, related to each other in terms of location and time. Most earthquakes clusters consists of small tremors, there is a theory that postulates that earthquakes can occur in a regular pattern. There is ample scope of research work for seismologists, engineers and scientists to develop reliable and reproducible predictions of earthquake happenings.

\section{REFERENCES}

[1]. International handbook of earthquake and engineering seismology- WHK Lee,H Kanamori, PC Jennings,and C Kisslinger (Academic press).

[2]. "Geology of crustal earthquake source", Sibson R.H(2002).

[3]. Watson,John;Watson, Kathie(January 7,19980) "Volcanoes and Earthquakes".

[4]. Donald Hyndman, David Hyndman (2009) "Chapter 3:Eathquakes and their causes".

[5]. IS 1893-2002 "Criteria for earthquake resistant design of structures".

[6]. IS 4326 "Earthquake resistant design and construction of buildings" Code of practice.

[7]. IS 13920 (1993) "Ductile detailing of reinforced concrete structures subjected to seismic forces", Code of practice.

[8]. Dr. Sudhir K. Jain "Earthquake engineering: problems and prospects" The Indian concrete journal, November 1994

\section{BIOGRAPHY}

Krishna Kumar - M. Tech. Scholar in Civil Engineering (Structural Design) from Ganga Institute of Technology and Management, Kablana, Jhajjar, Haryana (India) affiliated to Maharshi Dayanand University, Rohtak, Haryana (India). 